\title{
Warning Model of the Ionic Rare Earth Mine Slope Based on Creep Deformation Time Series
}

\author{
Dan Wang, ${ }^{1}$ Yun-zhang Rao $\mathbb{D}^{1}{ }^{1}$ Min Han, ${ }^{1}$ Liang Shi, ${ }^{1,2}$ Li Liu, ${ }^{1}$ and Mei-dao Zhang \\ ${ }^{1}$ School of Resources and Environmental Engineering, Jiangxi University of Science and Technology, Ganzhou 341000, China \\ ${ }^{2}$ School of Resources and Architectural Engineering, Gannan University of Science and Technology, Ganzhou 341000, China \\ Correspondence should be addressed to Yun-zhang Rao; raoyunzhang@jxust.edu.cn
}

Received 29 September 2021; Accepted 9 November 2021; Published 8 December 2021

Academic Editor: Yanan Gao

Copyright (C) 2021 Dan Wang et al. This is an open access article distributed under the Creative Commons Attribution License, which permits unrestricted use, distribution, and reproduction in any medium, provided the original work is properly cited.

\begin{abstract}
This paper takes the actual working conditions of leaching mining, with the Xikeng Rare Earth Mine in Anyuan County as the research object. The slope surface monitoring as a technical means is used to analyze the deformation characteristics, including cumulative displacement, velocity, and acceleration, and the leaching slope and establish an early warning system to assist with leaching production. The study shows that there are three stages in the process of ionic rare earth mine slope deformation, i.e., the initial stage with deformation velocity in 0.15 to $0.30 \mathrm{~mm} \cdot \mathrm{h}^{-1}$, the speed of the uniform deformation stage fluctuating but maintaining at -0.15 to $0.15 \mathrm{~mm} \cdot \mathrm{h}^{-1}$, and the accelerated deformation stage when the velocity and acceleration are 3 to 10 times or more than those of the initial deformation stage. The practice had proved that the monitoring system responded positively when an alarm based on the Local Outlier Factor (LOF) was issued so that the production process was in a safe state and no large-scale landslide disaster occurred. This study will provide theoretical and technical support for the safe and efficient mining of rare earth in situ leaching.
\end{abstract}

\section{Introduction}

In southern Jiangxi, ionic rare earth ore mining has gone through three steps of pool leaching, heap leaching, and in situ leaching [1-3]. Because pool leaching and heap leaching need to strip the topsoil and cause severe environmental damage and soil erosion, in situ leaching is the only mining method of the ionic rare earth ore in China. Based on active government promotion, in situ leaching has been rapidly developing $[4,5]$. However, the in situ leaching process is not perfect and will still bring environmental problems. During in situ leaching, a large amount of leaching solution is injected into the ore body, which destroys the mechanical balance of the slope and causes landslide disasters easily.

To solve the landslide in the in situ leaching process, Rao et al. [6] conducted on-site inspections of the rare earth mines with different deposit conditions and analyzed the main types of landslides and the catastrophic factors that caused them. And then, they formulated relevant prevention and control measures in the field. Wang et al. $[7,8]$ analyzed the deformation laws of rare earth slopes during leaching solution injection through field tests. They pointed out that different slope shapes will trigger different types of landslide modes after highstrength fluid injection, and then the corresponding reinforcement plan was put forward. Luo et al. [9] compared the differences in composition, gradation, cohesion, internal friction angle, etc., of the slope soil before and after rare earth leaching and then revealed the responding changes of the strength characteristic. Rao et al. [10] used logistic regression and introduced a landslide probability model to predict the certainty coefficient of rare earth slope landslides. The model provides essential theoretical support for landslide prediction and analysis. Wang et al. [11] studied the changes in ionic rare earth pore structure during the leaching process from a microscopic perspective. They pointed out that with the progress of leaching, the porosity and pore radius of rare earth ore gradually increase. The higher the concentration of the leaching agent within a certain range, the more pronounced this phenomenon becomes. This characteristic will cause the slope soil saturation to increase continually, and the mechanical strength gradually decreases.

The goal of rare earth landslide research is to monitor and control the landslide, grasp the deformation characteristics of 
the slope in real time, and control the landslide by adjusting the injection parameters to realize the safe and efficient mining of rare earth in situ leaching [12]. There are relatively few research studies on the early warning and control of rare earth slopes, especially the monitoring research based on actual leaching production. According to the actual working conditions of leaching mining, this paper uses slope surface monitoring as a technical means to analyze the deformation characteristics of the leaching slope. It proposes a warning model based on the Local Outlier Factor (LOF) for the rare earth slope landslide, real-time data, and a prediction tool for leaching mining. Finally, this study will provide theoretical and technical support for the safe and efficient mining of rare earth in situ leaching.

\section{Methods}

2.1. The Time Evolution Law of Slope Deformation and Failure. The key to establishing a landslide early warning model is to make accurate judgments on the stability of the slope. The current main research methods are the limit equilibrium method and the time series analysis method $[13,14]$. The application of the limit equilibrium method to analyze the stability of the slope is straightforward. The way is based on the static mechanical balance and Mohr-Coulomb criterion, which has a rigorous theoretical basis of mechanics [15]. However, landslide warning is a time-sensitive issue, especially for rare earth slopes [16]. With the progress of in situ leaching, soil mechanical properties, seepage, and infiltration lines will be changing, directly impacting the slope stability [17-19]. The time series analysis method evaluates slope stability based on field monitoring displacement and dynamically changing displacement with time. This method has the advantages of easy implementation, strong intuitiveness, and the ability to reflect dynamic changes of slopes. Therefore, it is widely used in the field of landslide warnings. Luo et al. [20] used the Chow split point test theory to accurately divide the landslide evolution process in combination with actual engineering examples and provided a basis for the critical landslide index. Xu et al. [21-23] decomposed the landslide displacement into a period term and a trend term and established a landslide displacement prediction model. Li et al. [24, 25] set a deformation rate early warning indicator model by studying the evolution law of different deformation stages. Qiang and Zeng [26] studied the cumulative displacement/velocity/accelerationtime curve in the process of landslide instability through a large number of examples. They proposed an early warning indicator model of the critical threshold of acceleration.

A large number of landslide monitoring data show that landslide deformation generally has the characteristics of creep. The deformation from the initial to the final slope instability needs to go through a process similar to the rheological test of rock and soil, such as initial deformation, constant velocity deformation, and accelerated deformation stages. And the cumulative displacement-time curve of landslide deformation can be split into three primary forms: gradual, sudden, and stable. Under different force conditions, the slope displacement-time curve is a series of displacement-time clusters [27], as shown in Figure 1.

In general geological disaster monitoring, it is often impossible to monitor the initial deformation stage of the landslide or even the complete constant velocity deformation stage. This feature is mainly because the slope had passed the initial deformation stage before the slope was monitored. And the slope has entered the phase of constant velocity deformation. In in situ leaching of ionic rare earth mines, the monitoring system is often arranged before leaching solution injection. Therefore, if the slope displacement is monitored on ionic rare earth slopes, a complete cumulative displacement-time curve can be obtained in theory. This feature is a tremendous advantage for establishing an ionic rare earth mine landslide warning based on the displacement-time curve.

The displacement-time curve of creep-type landslides has prominent three-stage characteristics. Still, it is tough to judge the landslide stage of the slope based solely on its cumulative displacement-time curve, so the speed-time curve and acceleration-time curve should be combined to make a comprehensive judgment. A typical gradual landslide as a demonstration template, as shown in Figure 2, is a characteristic gradual landslide cumulative displacementtime curve. The velocity can be obtained by calculating the first derivative of displacement versus time, and the acceleration can be obtained by calculating the second derivative.

Since the actual monitored cumulative displacementtime curve is a time series composed of discrete data points, it is impossible to obtain the velocity and acceleration by deriving the mathematical expression. This article will use days as the unit to calculate the average daily rate and then draw the rate points on the coordinate axis and connect them into a line. When calculating the acceleration, use the slope of the line connecting the two-day rate points as the approximate acceleration.

2.2. Landslide Warning Based on LOF. The triggering of landslides is often accompanied by severe deformation and abnormal detection data. Therefore, how to relativize anomaly detection becomes the key to landslide warning. Anomaly detection conducted in the field of statistics can be broadly classified into two categories, namely, distributionbased and depth-based methods [28-30]. For many interesting real-world datasets that exhibit more complex structures, there is another anomaly. These can be objects that are remote relative to their local neighborhood, especially relative to the density of the neighborhood. These outliers are considered "local" anomalies (or point anomalies). The Local Outlier Factor (LOF) is a recently developed outlier detection technology, which is a density-based outlier calculation method. The LOF value of the dependent variable at a specific measurement time can be calculated and compared with the corresponding independent variable to realize the identification of the cause of the abnormality [31]. Unlike the traditional anomaly method, which treats anomalies as binary attributes, it is based on density and has no distribution assumptions at all.

For a training dataset $\mathbf{x}=\left[\mathbf{x}_{1}, \mathbf{x}_{2}, \mathbf{x}_{3}, \cdots, \mathbf{x}_{i}, \cdots, \mathbf{x}_{n}\right] \in R^{D \times N}$, all $k$-nearest neighbors of $\boldsymbol{x}_{a}(a=1,2, \cdots, n)$ should be found 


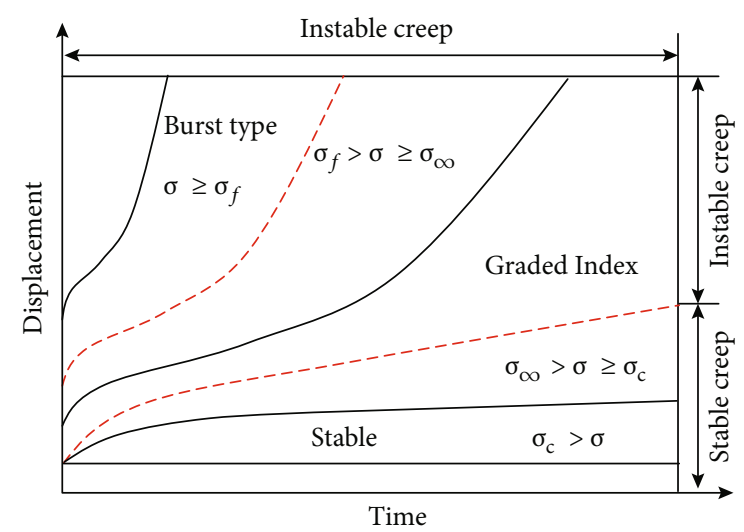

Figure 1: The curve type of slope displacement-time under different loading conditions, where $\sigma$ is the stress of the slip body, $\sigma_{\mathrm{c}}$ is the rock rheological limit, $\sigma_{\infty}$ is the long-term strength, and $\sigma_{\mathrm{f}}$ is the instantaneous intensity.

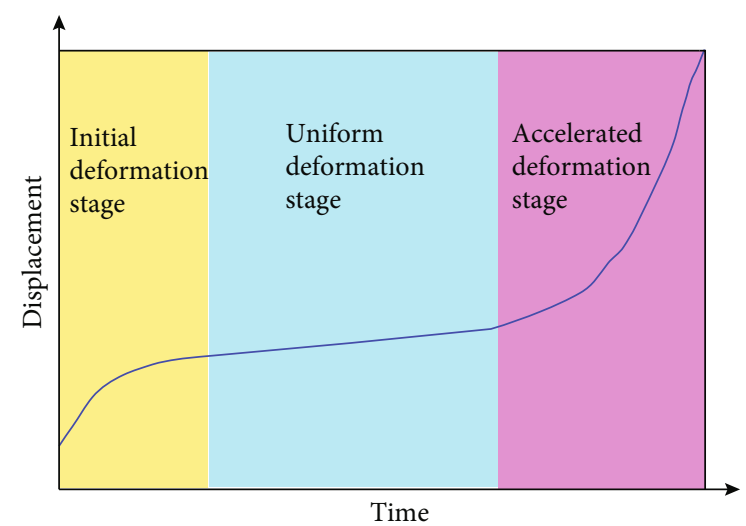

Figure 2: Displacement-time curve for the graded landslide.

out according to (1) and then the neighborhood set of $\mathbf{x}_{a}$ can be recognized as $\mathbf{K N N}\left(\mathbf{x}_{a}\right)$.

$$
d\left(\mathbf{x}_{a}, \mathbf{x}_{b}\right)=\sqrt{\sum_{n=1}^{D}\left|\mathbf{x}_{\mathrm{an}}-\mathbf{x}_{b n}\right|^{2}}, \quad a \neq b .
$$

The $k$-distance neighborhood of $\mathbf{x}_{a}$, denoted as $k$-distance $\left(\mathbf{x}_{a}\right)$, is defined as the Euclidean distance of $k$-nearest neighbors from $\mathbf{x}_{a}$, that is, the $k$ th smallest value of $d\left(\mathbf{x}_{a}, \mathbf{x}_{b}\right)\left(a \neq b, \mathbf{x}_{b}\right.$ $\in \mathbf{K N N}\left(\mathbf{x}_{a}\right)$ ). And the reachability distance of $\mathbf{x}_{a}$ with respect to $\mathbf{x}_{b}$ is defined as

$$
\operatorname{dist}\left(\mathbf{x}_{a}, \mathbf{x}_{b}\right)=\max \left\{k \text {-distance }\left(\mathbf{x}_{b}\right), d\left(\mathbf{x}_{a}, \mathbf{x}_{b}\right)\right\}
$$

The local reachability density of $\mathbf{x}_{a}$ is given by

$$
\operatorname{LRD}\left(\mathbf{x}_{a}, \mathbf{x}_{b}\right)=\frac{k}{\sum_{\mathbf{x}_{b} \in \operatorname{KNN}\left(\mathbf{x}_{a}\right)} \operatorname{dist}\left(\mathbf{x}_{a}, \mathbf{x}_{b}\right)} .
$$

The LOF of $\mathbf{x}_{a}$ is computed from the local reachability density of $\mathbf{x}_{a}$ and that of $\mathbf{x}_{b} k$-nearest neighbors as

$$
\operatorname{LOF}\left(\mathbf{x}_{a}, \mathbf{x}_{b}\right)=\frac{1}{k} \sum_{\mathbf{x}_{b} \in \operatorname{KNN}\left(\mathbf{x}_{a}\right)} \frac{\operatorname{LRD}\left(\mathbf{x}_{a}\right)}{\operatorname{LRD}\left(\mathbf{x}_{b}\right)}
$$

The LOF is the ratio of the average density of $\mathrm{KNN}\left(\mathbf{x}_{a}\right)$ to the density of $\mathbf{x}_{a}$. The larger the $\operatorname{LOF}\left(\mathbf{x}_{a}\right)$ value, the more probable it is to be an outlier. If $\mathbf{x}_{a}$ is not an anomaly, $\operatorname{LOF}\left(\mathbf{x}_{a}\right)$ should be close to 1 because the density of $\mathbf{x}_{a}$ and $\operatorname{KNN}\left(\mathbf{x}_{a}\right)$ is similar. But if $\mathbf{x}_{a}$ is an outlier, $\operatorname{LOF}\left(\mathbf{x}_{a}\right)$ should be distinctly larger than 1 because the relative density of $\mathbf{x}_{a}$ to $\mathbf{K N N}\left(\mathbf{x}_{a}\right)$ is small. Specifically, if $\operatorname{LOF}\left(\mathbf{x}_{a}\right)$ is less than or equal to $1, \mathbf{x}_{a}$ must be deep into a cluster. However, this value cannot be used to judge whether a sample is an anomaly or not. Because the acceptable range of LOF values would vary among applications, a control limit or threshold is needed to judge an anomaly. According to the previous works, $\mathbf{x}_{a}$ is judged as an outlier if the $\operatorname{LOF}\left(\mathbf{x}_{a}\right)$ is a trigger threshold determined by kernel density estimation (KDE) with LOF. The warning information will be sent simultaneously (classification of warning levels), as shown in Table 1.

\section{Study Area}

3.1. Geological Conditions of the Xikeng Rare Earth Mine. The test ore block was selected at a relatively flat hillside in the Xikeng Rare Earth Mine of Anyuan County. It is located in the south of China, which lies within the latitude $25^{\circ} 11^{\prime}$ $09^{\prime \prime}$ to $25^{\circ} 11^{\prime} 41^{\prime \prime} \mathrm{N}$ and longitude $115^{\circ} 04^{\prime} 00^{\prime \prime}$ to $115^{\circ} 04^{\prime}$ $51^{\prime \prime} \mathrm{E}$ and reports an area of about $2.0 \mathrm{~km}^{2}$ (Figure 3). The Xikeng Rare Earth Mine in Anyuan mainly occurs in the fully weathered layer formed by streaked migmatite, which is a typical fully overlying type and has no waterproof floor at the bottom of the stope. The rocks are characterized by granitic metamorphic texture, metasomatic texture, and residual texture, showing strip strip mark, eyeball, and massive structure and inconspicuous gneissic structure. Rocks are mostly brick red, light yellowish-brown, slightly graywhite in some areas, and loose in structure. The matrix protolith is mainly granulite and schist, and the mineral composition is composed of feldspar, quartz, and biotite and locally of muscovite and star-shaped black minerals. Most feldspars in the weathering crust have been replaced by kaolin, which is soil-like, with a smooth and greasy hand feeling. The quartz particles are small and uniform, and the content is small. Therefore, the permeability of ore soil is extremely poor. According to production exploration, the ore block area is $3640.82 \mathrm{~m}^{2}$, the ore body thickness is $10.82 \mathrm{~m}$, the average grade is $0.08 \%$, the ore body volume is $39399 \mathrm{~m}^{3}$, and the REO reserve of the $121 b$ ore block is $47.46 \mathrm{t}$. Therefore, this test site has outstanding representativeness and reference.

The weathering crust mainly developed in the ore section primarily consists of streaks of mixed rocks, exposed below the elevation of $340 \mathrm{~m}$, with a surface spread. As most hillsides have been developed into terraces to grow navel oranges, the vegetation in the study area is not set for the type 
TABLE 1: Warning levels adopted for the early warning system [28, 31].

\begin{tabular}{|c|c|c|}
\hline Warning level & Triggers & Response \\
\hline WL1-red alert & $\operatorname{LOF}\left(\mathbf{x}_{a}\right) \geq 99 \%$ & $\begin{array}{l}\text { Immediately stop the injection flow rate, and investigate the } \\
\text { abnormal points of velocity and acceleration }\end{array}$ \\
\hline WL2-orange alert & $99 \%>\operatorname{LOF}\left(\mathbf{x}_{a}\right) \geq 95 \%$ & $\begin{array}{l}\text { Investigate the abnormal points of velocity and acceleration, } \\
\text { and slow down the injection rate as appropriate }\end{array}$ \\
\hline
\end{tabular}

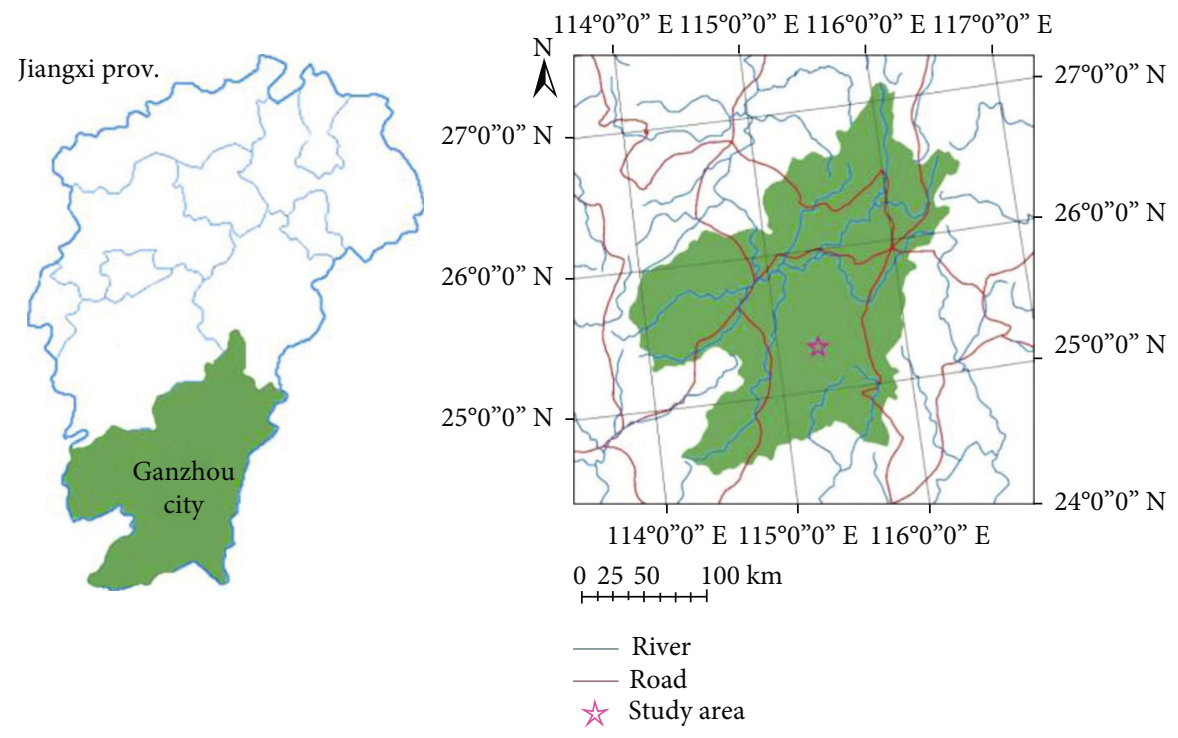

FIGURE 3: Location map of the study area.

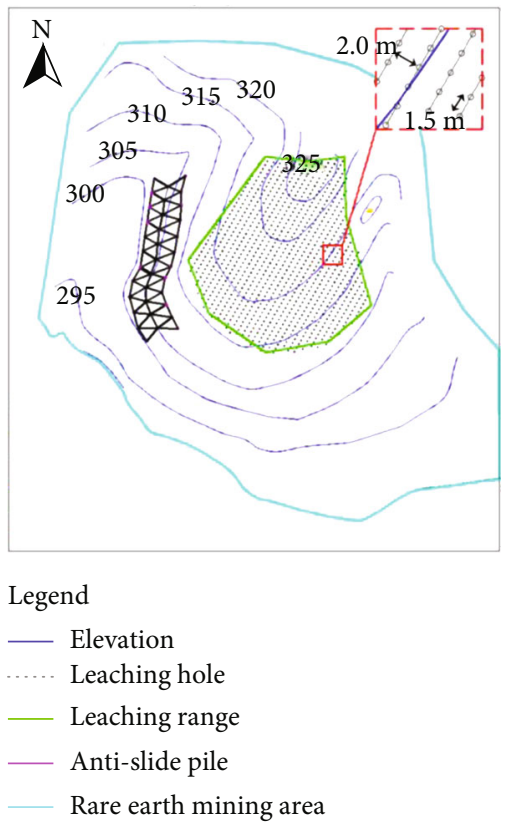

(a)

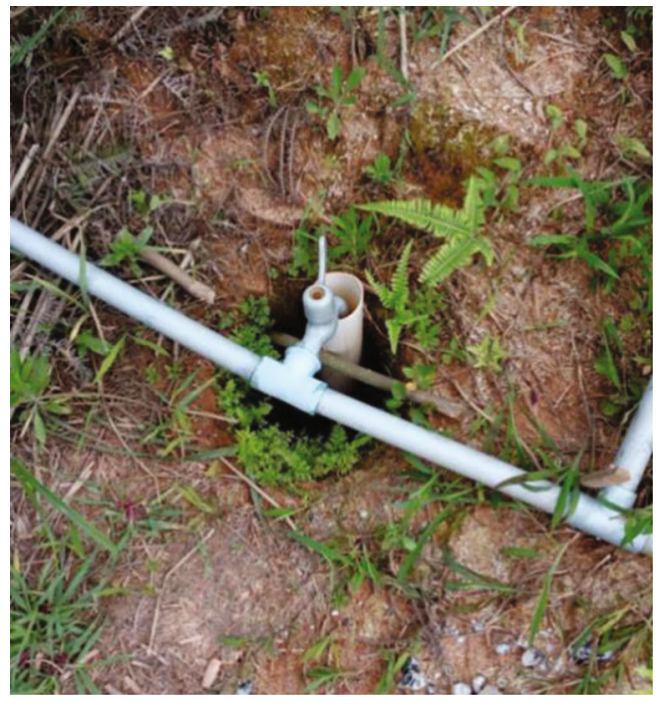

(b)

Figure 4: Schematic diagram of the leaching system. (a) The layout of the injection hole layout. (b) The installation of the injection hole. 


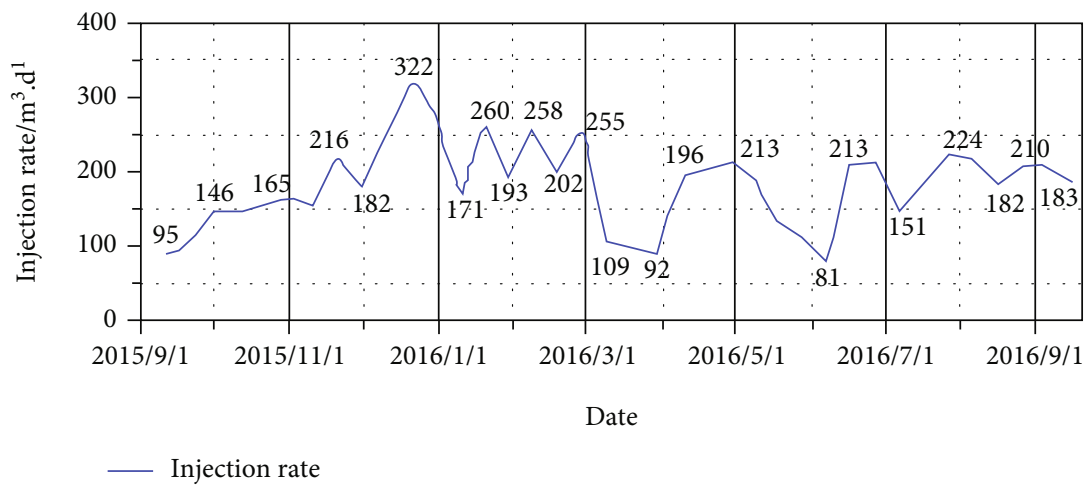

FIGURE 5: The record of injection rate data.
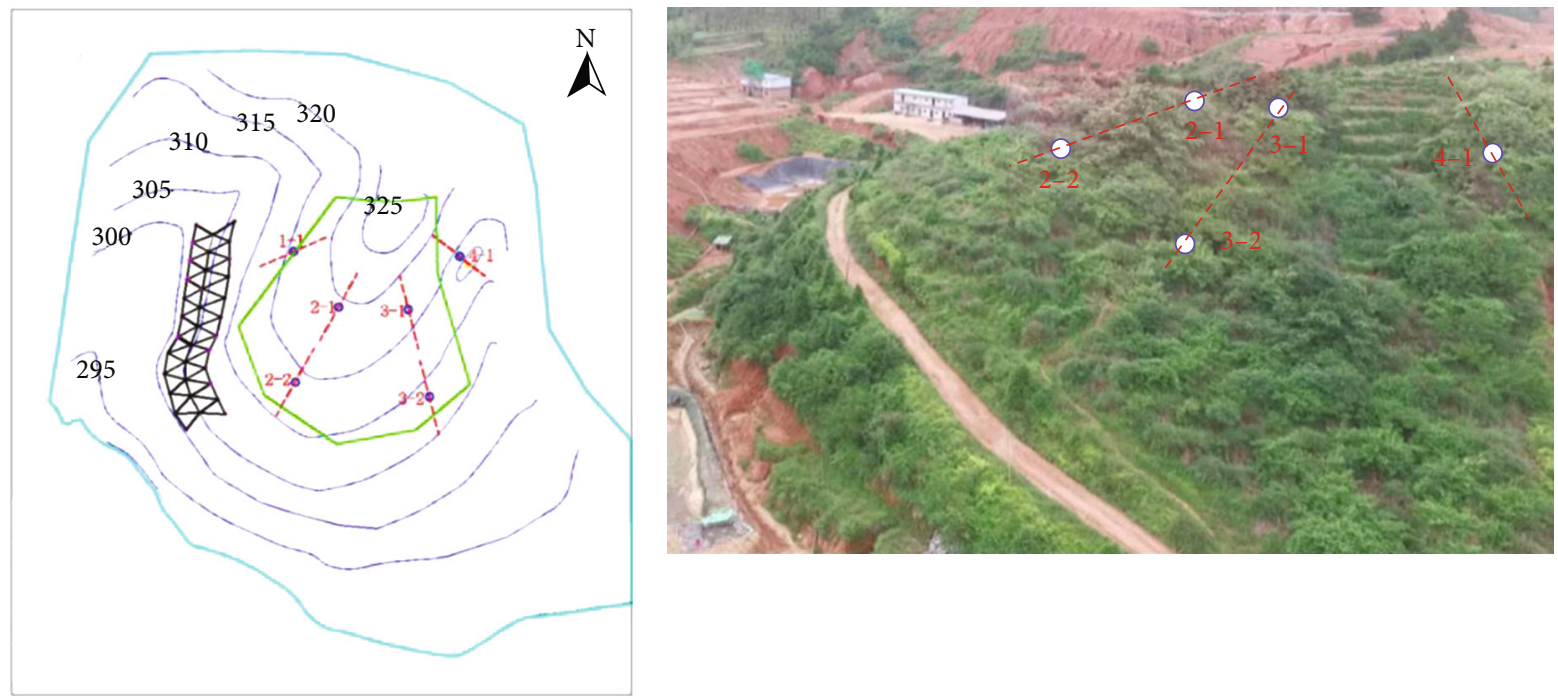

Legend

- Elevation

a-o Montoring line

_ Leaching range

— Anti-slide pile

Rare earth mining area

(a)

(b)

Figure 6: Schematic diagram of the monitoring system. (a) The design of the monitoring point. (b) The location of the monitoring point in the field.

of rare earth mines because $70 \%$ of the southern ionic rare earth mineral resources belong to the fully covered class, so this test site has outstanding representativeness and reference.

\subsection{In Situ Leaching Parameters of the Ionic Rare Earth Ore.} The injection holes are arranged in a checkerboard pattern. The mesh size of the injection holes is $1.5 \mathrm{~m} \times 2 \mathrm{~m}$; that is, the row spacing is $2.0 \mathrm{~m}$, the hole spacing is $1.5 \mathrm{~m}$, and the arrangement is staggered. The hole diameter is $\Phi 180 \mathrm{~mm}$, and the depth of injection holes is 1.5 to $2.0 \mathrm{~m}$ [32]. After the injection hole is excavated, insert a $50 \mathrm{~mm}$ diameter PVC pipe into it to ensure that the injection hole will not collapse during leaching-the schematic diagram of the leaching system is shown in Figure 4.

According to the ore volume of the mined block, the total liquid injection amount is calculated according to the solidliquid ratio (volume ratio) of $1: 0.33$. The leaching liquid is an aqueous solution of ammonium sulfate with a $1 \%$ to $2 \%$ concentration. The original design of the injection flow rate is 250 to $270 \mathrm{~m}^{3} \cdot \mathrm{d}^{-1}$. Still, due to the poor permeability of the ore soil, in the actual injection process, the excessively high injection flow rate cannot completely penetrate the soil block and overflow the injection hole. For this reason, the injection flow rate is reduced to 180 to $220 \mathrm{~m}^{3} \cdot \mathrm{d}^{-1}$, and the average 

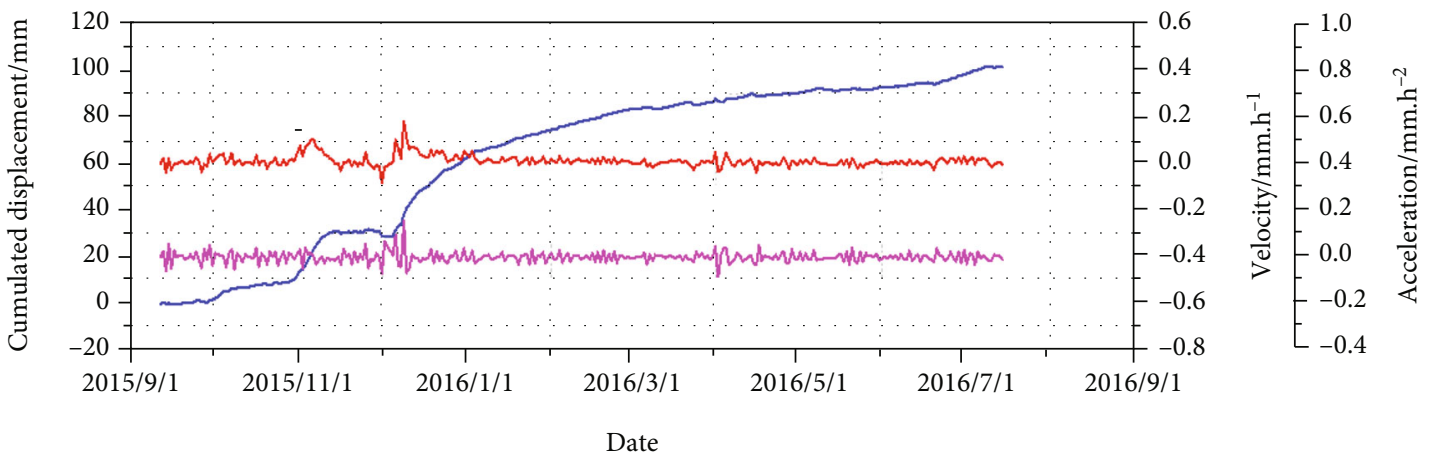

(a)
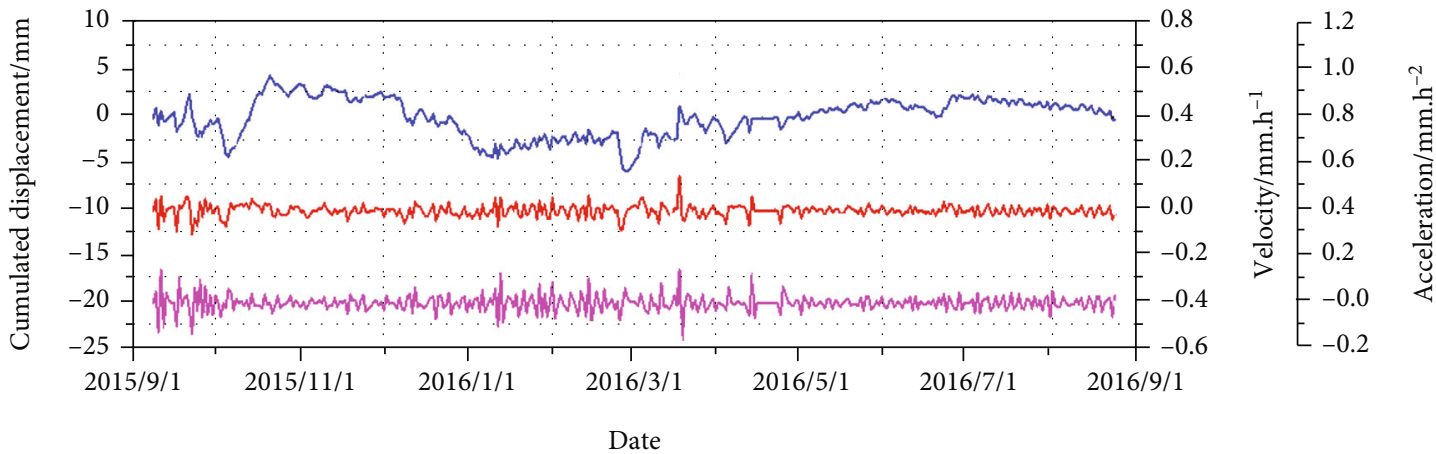

(b)
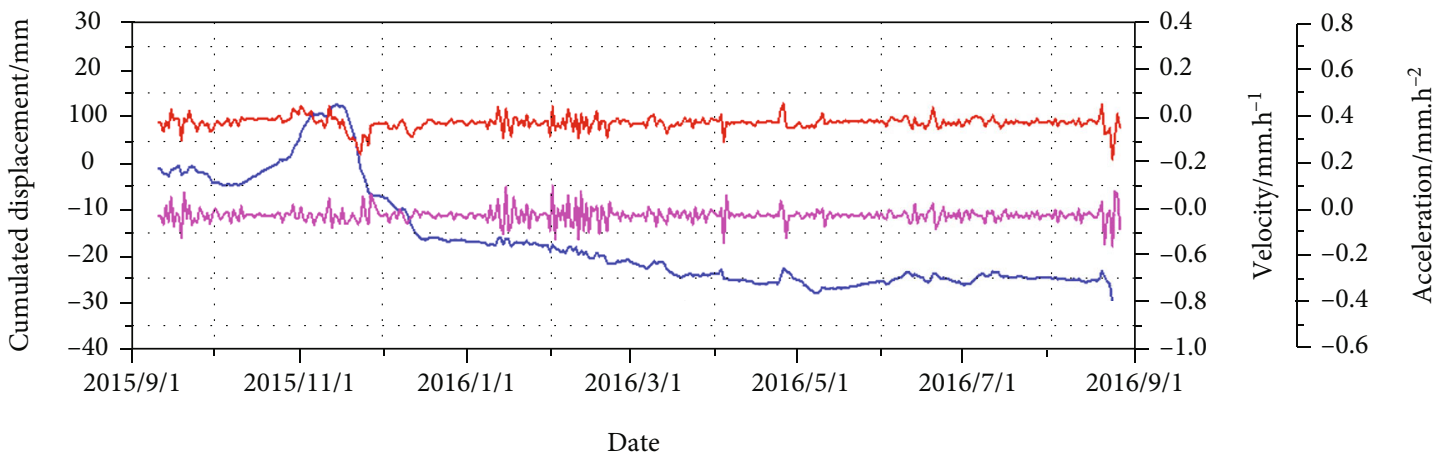

(c)

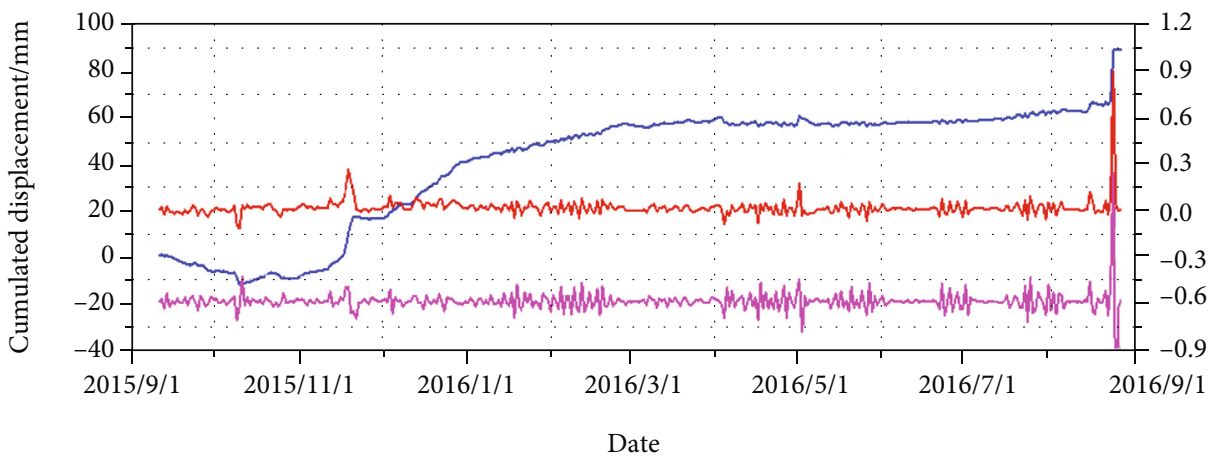

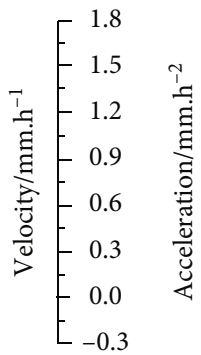

(d)

Figure 7: Continued. 


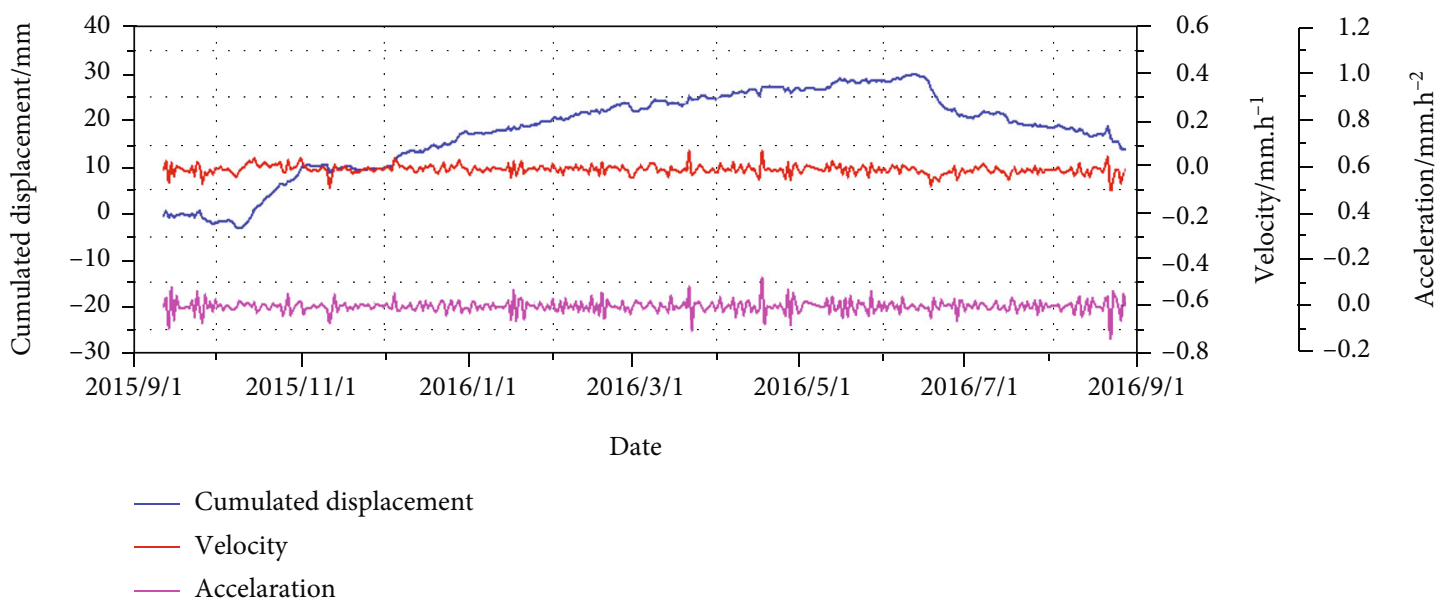

(e)

FIGURE 7: Archived monitoring data: (a) 1-1 point, (b) 2-1 point, (c) 3-1 point, (d) 3-2 point, and (e) 4-1 point.

injection rate is approximately $206.4 \mathrm{~m}^{3} \bullet \mathrm{d}^{-1}$. In case of heavy rainfall or monitoring of severe slope deformation, it is necessary to reduce the injection flow rate greatly. The specific injection data is shown in Figure 5.

3.3. Layout of Monitoring Points. Three-dimensional numerical simulation is used to find out the most easily unstable area of the three-dimensional slope, and this area is regarded as the key monitoring area. The plastic zone is obtained by FLAC3D according to the homogeneous slope parameters, and if the shear-p region has been contiguous, it is generally believed that the formation of a plastic zone is a sign of the instability of the slope region, and this area is regarded as the key monitoring area of the slope, and survey lines are arranged in this area, as shown in Figure 6. Four survey lines are arranged, as shown in Figure 6. There is 1 surface displacement meter on the No. 1 survey line, there are 2 displacement meters on each of the No. 2 and No. 3 survey lines, and there is 1 displacement meter on the No. 4 survey line [33]. All sensors are connected to the system server through the ionic rare earth mine slope online monitoring system independently developed by this research group. The system is set to collect a round of data every half an hour.

\section{Results and Discussion}

4.1. Achievement and Analysis of Monitoring Data. The surface vegetation coverage of the ionic rare earth mine in southern Jiangxi before leaching is relatively high, and its slope itself is not steep, approximately $30^{\circ} \sim 40^{\circ}$. According to experience and related calculations, the slope is stable before the in situ leaching. The stability of the slope is high, and the stability of the slope is reduced mainly because of the active mining of injecting the leaching liquid into the slope. Therefore, what we have to prevent is the landslide of the slope during the leaching period.

After installing the slope online monitoring system, the Xikeng Rare Earth Mine was mined with liquid following con- ventional procedures. During the whole cycle from the beginning of liquid injection to the completion of mining, the surface displacement data was monitored; from September 11, 2015 , to September 16, 2016, the monitoring period will be approximately one year. Before drawing the displacementtime curve, you first need to write a program with SQL and C ++ to classify and summarize all the data and find the average displacement. Since the data monitored by each sensor reaches nearly 10,000, it will not be listed in detail here.

Figure 7 shows the archived data of displacement, velocity, and acceleration with time from the monitoring sections of 1-1, 2-1, 3-1, 3-2, and 4-1. And the 2-2 section was destroyed by workers inadvertently in mining. The data is invalid, so it is not listed.

When the slope shows a landslide, the surface displacement increment shows a sudden change and the speed and acceleration show almost exponential growth. In the figure, the speed and acceleration second only to the acceleration deformation stage appear in the initial deformation stage. Comparing other data with no signs of landslides (Figures 7(b), 7(c), and 7(e)), Figures 7(a) and 7(d) have very similar trends. The historical speed and acceleration peaks during the monitoring period all appeared in the previous period. It is in the initial deformation stage and then has been in the stable constant velocity deformation stage. It can be predicted that if the injection continues, the possibility of a landslide in the 1-1 displacement gauge is very high, the same as the 3-2 displacement gauge.

Figure 7(b) shows that the displacement increments of the surface displacement meters at 2-1 are minimal and fluctuate around 0, and Figure 7(c) indicates that the displacement increments of the surface displacement meters at 3-1 are decreasing. Therefore, these two places are relatively stable, and there is no risk of landslides. In Figure 7(e), in the surface displacement meter at the $4-1$ point, the peak velocity was $0.0748 \mathrm{~mm} \cdot \mathrm{h}^{-1}$ for the first time on October 16, 2016; the second time was on April 1, 2016, and its value was $0.084 \mathrm{~mm} \cdot \mathrm{h}^{-1}$; the last peak velocity occurred on April 29, 2016, and after a steady lowspeed deformation, the displacement increment began to 


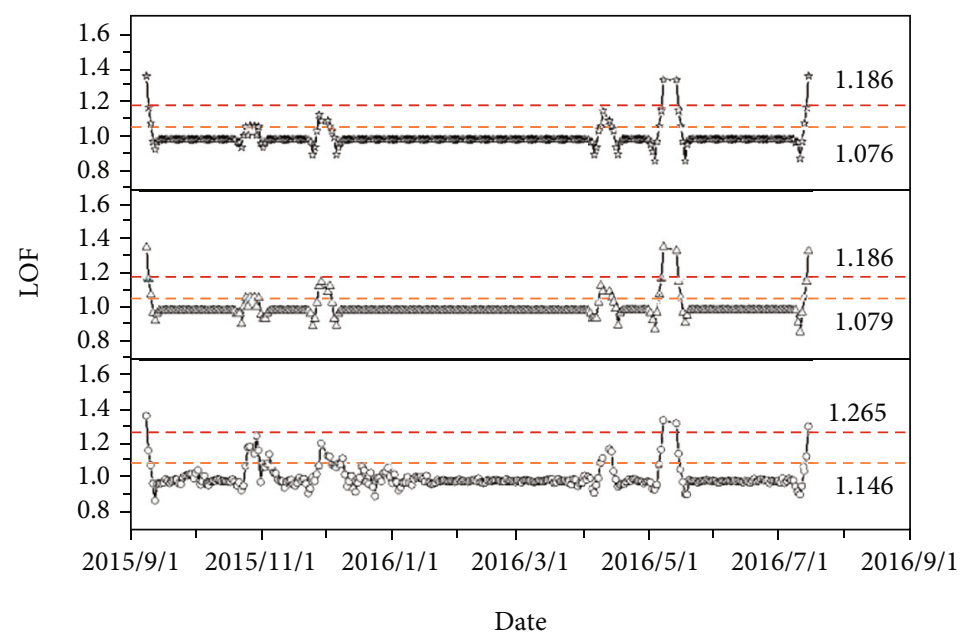

(a)

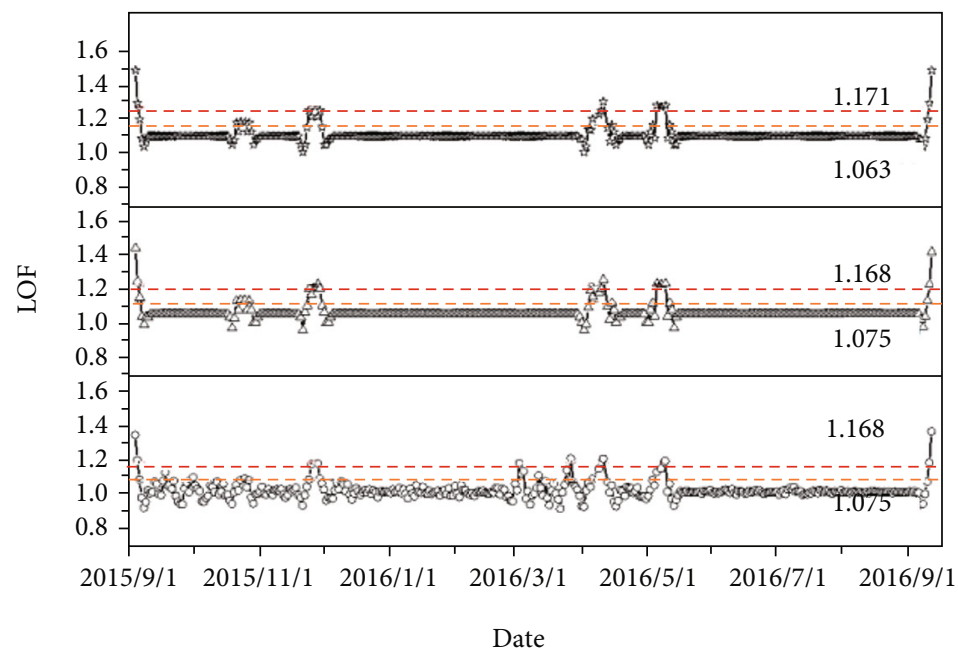

(b)

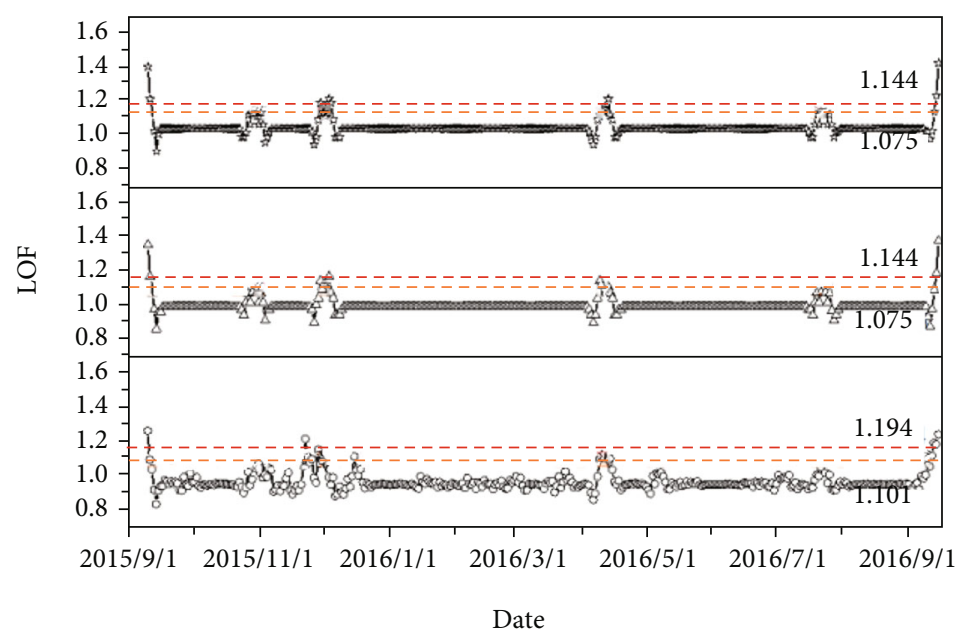

(c)

Figure 8: Continued. 


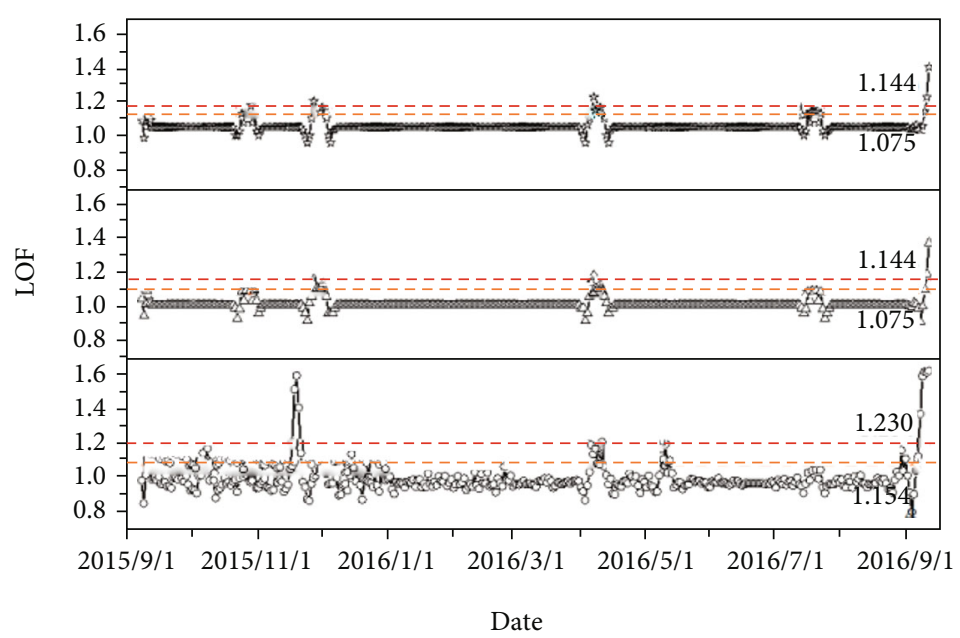

(d)

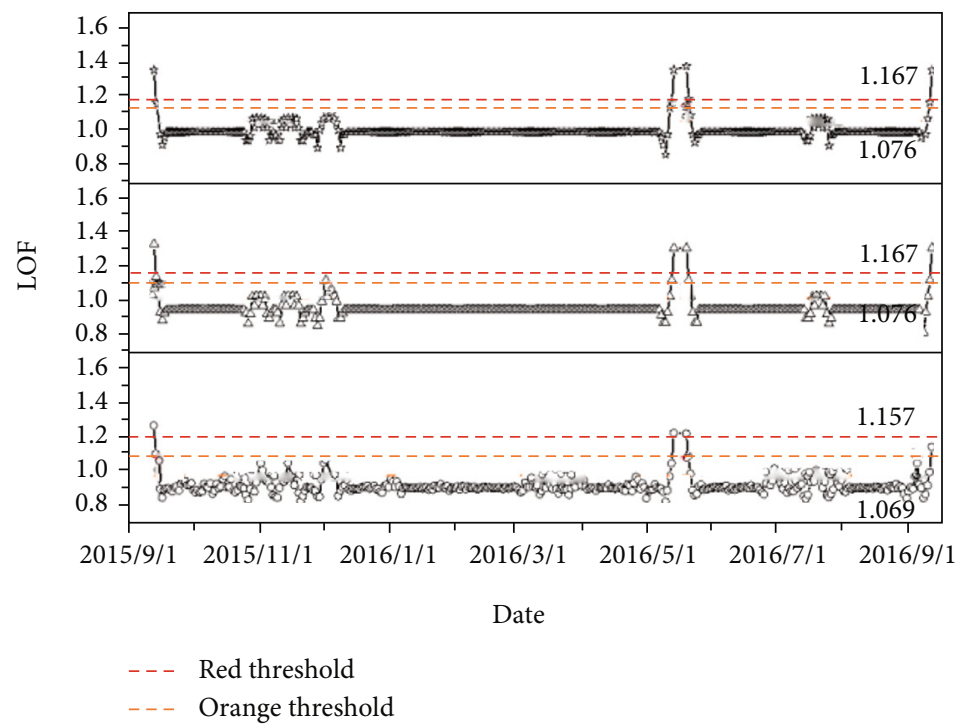

(e)

FIGURE 8: LOF value and warning threshold of the deformation data: (a) 1-1 point, (b) 2-1 point, (c) 3-1 point, (d) 3-2 point, and (e) 4-1 point.
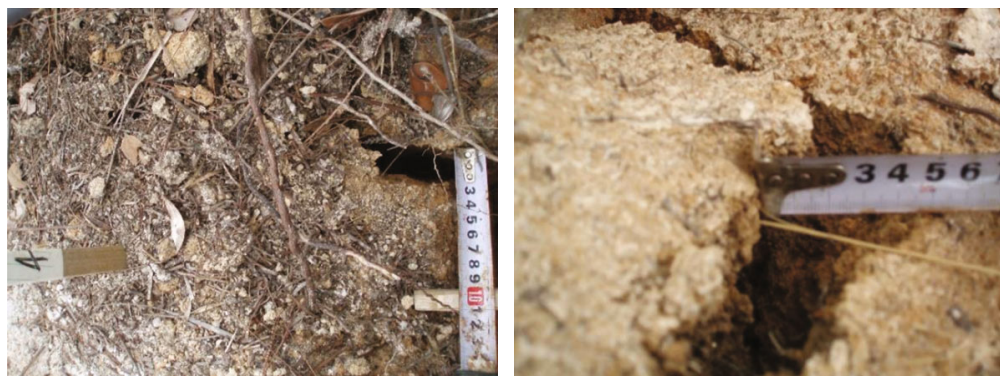

FIGURE 9: Fresh crack appeared in the monitoring range.

decrease. First of all, it can be seen that the surface displacement deformation at 4-1 is relatively gentle. Second, after the last speed peak appears, the displacement increment begins to fall back to $0 \mathrm{~mm}$, so it can be judged that this place is a stable creep, with the changing trend being the same as the steady creep curve in Figure 1.
4.2. Anomaly Detection and Warning of the Deformation Data. After the monitoring data is preprocessed, the LOF value of each monitoring point is calculated, respectively, as shown in Figure 8. During the injection process, when the LOF value of the deformation data reaches the orange warning value, the injection staff immediately responded 
by reducing the injection rate and surveying the abnormal points; if the LOF value continues to rise, when it reaches the red warning value, the injection is stopped immediately.

According to the on-site survey, when the LOF value of the monitoring point reached the red warning value for the first time, a significant crack appeared in the area of the monitoring point and the apparent width was close to $20 \mathrm{~mm}$, as shown in Figure 9. After the monitoring system issued an early warning, the leaching warning system quickly notified the operators onsite to stop the injection and leave the site. After the deformation data is stable, restart the injection system.

\section{Conclusions}

According to the actual working conditions of leaching mining in the Xikeng Rare Earth Mine in Anyuan County, this paper uses slope surface monitoring as a technical means to analyze the deformation characteristics of the leaching slope. The main conclusions are as follows:

(1) There is an apparent three-stage displacement and deformation, namely, initial deformation, uniform deformation, and accelerated deformation, in the in situ leaching process of the ionic rare earth mine slope. That is, the landslide of the rare earth mine slope is creeping

(2) The deformation speed of the rare earth mine slope at the initial stage is 0.15 to $0.30 \mathrm{~mm} \cdot \mathrm{h}^{-1}$, and the rate at the constant deformation stage is -0.15 to $0.15 \mathrm{~mm} \cdot \mathrm{h}^{-1}$. When entering the accelerated deformation stage, the speed and acceleration are 3 to 10 times or even higher than those of the initial deformation stage. The deformation speed of the rare earth mine slope shows a response slightly lagging behind the acceleration, and the acceleration shows a more stable trend

(3) The LOF value based on the deformation of multiple measuring points has high self-adjustment ability and good robustness. The time course of the LOF value can quantitatively reflect the stage of landslide deformation and avoid wrong judgment caused by accidental factors. This method is applied in the early warning of landslides in rare earth leaching mining and effectively guides safe production

\section{Data Availability}

The data that support the findings of this study are available from the corresponding author (VS) upon reasonable request.

\section{Conflicts of Interest}

The authors declare that there are no conflicts of interest regarding the publication of this paper.

\section{Acknowledgments}

This work was financially supported by the National Natural Science Foundation of China (Grant No. 51964014) and the Education Department of Jiangxi Province (Grant No. GJJ209414).

\section{References}

[1] S.-h. Yin, W. Chen, X.-l. Fan, J.-m. Liu, and L.-b. Wu, "Review and prospects of bioleaching in the Chinese mining industry," International Journal of Minerals, Metallurgy and Materials, vol. 28, no. 9, pp. 1397-1412, 2021.

[2] M. Haschke, J. Ahmadian, L. Zeidler, and T. Hubrig, "In-situ recovery of critical technology elements," Procedia Engineering, vol. 138, pp. 248-257, 2016.

[3] S. Yin, X. Chen, R. Yan, and L. Wang, "Pore structure characterization of undisturbed weathered crust elution-deposited rare earth ore based on X-ray micro-CT scanning," Minerals, vol. 11, no. 3, pp. 236-252, 2021.

[4] Y. X. Li, L. Zhang, and X. M. Zhou, "Resource and environment protected exploitation model for ion-type rare earth deposit in southern of China," Rare Earths, vol. 31, pp. 80-86, 2010.

[5] W. Chen, D. Li, T. Ma, H. Fu, and Y. Du, "Stability analysis of a slope considering two reinforcement processes," Geofluids, vol. 2020, 2020.

[6] R. Rao, M. C. Li, and S. B. Shu, "Experimental study on landslide features and countermeasures of in-situ leaching stope of ion-type rare earth mines," Rare Earths, vol. 37, pp. 26-31, 2016.

[7] S. L. Hu, B. G. Hong, and S. H. Luo, "Effect of in-situ leaching for rare earth mining to slope stability," Journal of Engineering Geology, vol. 25, pp. 110-116, 2017.

[8] L. Wang, C. Liao, Y. Yang, H. Xu, Y. Xiao, and C. Yan, "Effects of organic acids on the leaching process of ion-adsorption type rare earth ore," Chinese Rare Earths, vol. 35, no. 12, pp. 1233-1238, 2017.

[9] S. H. Luo, L. Yuan, and G. S. Wang, "The effect of leaching on the strength of ion-adsorption rare-earth ore," Nonferrous Metals Science and Engineering, vol. 4, pp. 58-61, 2013.

[10] Y. Z. Rao, X. Y. Zhang, X. Z. Li et al., "Probability of landslide in the application of slope stability analysis," Journal of Catastrophology, vol. 31, pp. 7-11, 2016.

[11] X. J. Wang, Y. X. Li, and G. L. Huang, "Changes of pore structure in leaching ion-adsorption type rare earth ore," Journal of the Chinese Rare Earth Society, vol. 35, pp. 528-536, 2017.

[12] Q. Du, G. Li, Y. Zhou et al., "Deformation monitoring in an alpine mining area in the Tianshan Mountains based on SBAS-InSAR technology," Advances in Materials Science and Engineering, vol. 2021, 15 pages, 2021.

[13] K. Hu, C. W. Chen, and P. Zhang, "Real-time monitoring of dynamic stability coefficient and displacement criterion of the creep slope," Chinese Journal of Rock Mechanics and Engineering, vol. 35, pp. 1377-1385, 2016.

[14] W. Huangfu, W. Wu, X. Zhou et al., "Landslide geo-hazard risk mapping using logistic regression modeling in Guixi, Jiangxi, China," Sustainability, vol. 13, no. 9, p. 4830, 2021.

[15] H.-J. Hou, B. Wang, Q.-X. Deng, Z.-W. Zhu, and F. Xiao, "Model experimental study on stress transfer and redistribution in a clay landslide under surcharge load," Advances in Materials Science and Engineering, vol. 2020, 14 pages, 2020. 
[16] Q. Meng, W. Li, F. Raspini et al., "Time-series analysis of the evolution of large-scale loess landslides using InSAR and UAV photogrammetry techniques: a case study in Hongheyan, Gansu Province, Northwest China," Landslides, vol. 18, no. 1, pp. 251-265, 2021.

[17] S. Yin, Y. Shao, A. Wu, S. Wang, and G. Li, "The effect of ferrous ions on hydraulic conductivity in fine tailings," Engineering Geology, vol. 260, article 105243, 2019.

[18] S. Yin, Y. Shao, A. Wu, H. Wang, X. Liu, and Y. Wang, "A systematic review of paste technology in metal mines for cleaner production in China," Journal of Cleaner Production, vol. 247, article 119590, 2019.

[19] J. Huazhe, W. Shufei, Y. Yixuan, and C. Xinming, "Water recovery improvement by shearing of gravity-thickened tailings for cemented paste backfill," Journal of Cleaner Production, vol. 245, article 118882, 2019.

[20] W. Q. Luo, F. A. Li, and X. S. Liu, "Volution stage division of landslide based on analysis of multivariate time series," Earth Science, vol. 41, pp. 711-717, 2016.

[21] Y. Liu, H. M. Yu, and F. B. Liu, "Landslide displacement nonlinear time series prediction model," Geological Science and Technology Information, vol. 35, pp. 203-207, 2016.

[22] M. Meng, Z. Q. Chen, and D. B. Huang, "Displacement prediction of landslide in Three Gorges Reservoir are based on H-P filter, ARIMA and VAR models," Rock and Soil Mechanics, vol. 37, pp. 552-560, 2016.

[23] F. Xu, Y. Wang, and J. Du, "Study of displacement prediction model of landslide based on time series analysis," Chinese Journal of Rock Mechanics and Engineering, vol. 30, pp. 746-751, 2011.

[24] C. Li, J. Zhu, and B. Wang, "Critical deformation velocity of landslides in different deformation phases," Chinese Journal of Rock Mechanics and Engineering, vol. 35, pp. 1407-1414, 2016.

[25] M. Barla and F. Antolini, "An integrated methodology for landslides' early warning systems," Landslides, vol. 13, pp. 215-228, 2016.

[26] X. Qiang and Y. Zeng, "Research on acceleration variation characteristics of creep landslide and early-warning prediction indicator of critical sliding," Chinese Journal of Rock Mechanics and Engineering, vol. 28, pp. 1099-1106, 2009.

[27] X. J. Dong, Q. Xu, and C. Tang, "Characteristics of landslide displacement-time curve by physical simulation experiment," Journal of Engineering Geology, vol. 23, pp. 401-407, 2015.

[28] J. Hu, F. H. Ma, and S. H. Wu, "Anomaly identification of foundation uplift pressures of gravity dams based on DTW and LOF," Structural Control and Health Monitoring, vol. 25, no. 5, article e2153, 2018.

[29] J. Lee, B. Kang, and S. H. Kang, "Integrating independent component analysis and local outlier factor for plant- wide process monitoring," Journal of Process Control, vol. 21, no. 7, pp. 1011-1021, 2011.

[30] C. C. Hsu, L. S. Chen, and C. H. Liu, "A process monitoring scheme based on independent component analysis and adjusted outliers," International Journal of Production Research, vol. 48, pp. 1727-1743, 2009.

[31] T. H. Yang, H. Wang, and X. Dong, "Current situation, problems and countermeasures of intelligent evaluation of slope stability in open pit," Journal of the China Coal Society, vol. 45, pp. 2277-2295, 2020.
[32] Z. Zhang, Z. He, J. Yu, Z. Xu, and R. Chi, "Novel solution injection technology for in-situ leaching of weathered crust elutiondeposited rare earth ores," Hydrometallurgy, vol. 164, pp. 248256, 2016.

[33] T. Zhigang, Z. Chun, W. Yong, W. Jiamin, H. Manchao, and Z. Bo, "Research on stability of an open-pit mine dump with fiber optic monitoring," Geofluids, vol. 2018, 20 pages, 2018. 